\title{
SUICÍDIOS, PSICOLOGIA E VÍNCULOS: UMA LEITURA PSICOSSOCIAL
}

\section{Rogério Lustosa Bastos}

Resumo: Este artigo, pensando o suicídio por um contínuo existencial com diferentes graus (primeiros graus de suicídio - desvelando-se por fantasias inconscientes; graus intermediários - caracterizando-se por tentativas de suicídio; graus extremos - destacando-se pelo suicídio fatal), ainda o debate pela perspectiva de Freud e Jung. Mas busca-se, sobretudo, relacionar o suicídio ao processo psicossocial, estudado aqui pelo vínculo. Esse, basicamente apreendido como um padrão vincular, inicia-se na família (socialização primária). Assim, diante da hipótese de se ter vivido sob padrão vincular com pendor à desestrutura (relacionada à dificuldade de cada membro se diferenciar), esse padrão tende a se repetir pela socialização secundária: grupo conjugal, de trabalho, de educação, de religião, etc. Enfim, sem o apoio devido, em alguns casos essa dificuldade leva às tentativas e aos suicídios fatais. Tanto essa discussão quanto o processo psicossocial serão desenvolvidas aqui, principalmente, pela visão institucional de Bastos (2001b), Bleger (1984), Guirado (2004).

Palavras-chave: Suicídios. Processo psicossocial.Vínculos.

\section{Introdução}

\author{
"Faço o que eu faço para não ser transparente" \\ (Arthur Bispo do Rosário) $^{1}$
}

1 Arthur Bispo do Rosário viveu praticamente 50 anos internado na Colônia Juliano Moreira, sob regime de total discriminação, imposto pela psiquiatria tradicional, pela sociedade e pela sua família. Nesse período, ele, como outros pacientes ditos crônicos, jamais foi procurado por algum familiar. Diante da perda desses 
Curiosas são certas composições existentes no humano, tal como a questão do suicídio e a do grupo social. Em tese, mesmo não se negando a singularidade desse ato, analisar esses fatores isoladamente seria tão inverossímil como defender que o ar que respiramos continuaria a ser o ar se separássemos o oxigênio da composição que alimenta nossos pulmões. Dessa forma, pensando o suicídio como um acontecimento complexo que ocorre principalmente entre a vida pessoal e a coletiva, este artigo pretende discutir a autodestruição por um processo psicossocial, que se denota pela análise de patamares básicos que o subscrevem. Tais patamares básicos, em síntese, são: o patamar do território do dito individual, o patamar do território das inter-relações, o patamar do território das instituições, o do território da comunidade, o do território do contexto macrossocial ou da história (v. Figura 2/ sessão terceira deste trabalho). Em outras palavras, diante da ocorrência do autocídio, em vez de adotarmos explicações, as quais, a priori, indicam que são fatos exclusivamente relacionados à esfera do individual ou são fatos que se reduzem a explicações sociais, vamos tentar delinear as suas possíveis causas pelos diferentes patamares citados. Obviamente que, de uma parte, frente a determinados suicídios, em função de particular contexto, pode ser que o fator familiar (ou inter-relacional) prepondere sobre os demais; de outra parte, junto de outro contexto, pode ser que prepondere o fator do território do social como um todo, ou o fator individual e assim por diante. Detalhe: tendo em conta que do prisma psicossocial a autodestruição tende a se relacionar com uma pluralidade de fatores ou patamares, ainda considerando a singularidade desse ato, como vimos, é em função de cada contexto que poderemos ler qual desses fatores ou patamares poderá estar preponderando na tentativa da morte de si mesmo ou no suicídio fatal.

Além de pensar o suicídio pelo processo psicossocial e de contar com uma discussão por dois principais pontos de vistas psicológicos (de Freud e de Jung), o artigo chamará bastante a atenção para um outro ponto significativo neste estudo: a questão dos vínculos.

Isso implica, em primeiro lugar, que uma das questões principais que perpassa os diferentes patamares e pode influir na tendência para a autodestruição é a referida questão. Vendo de outro modo, gestados a partir do agrupamento familiar por inter-relações peculiares, os vínculos têm significativa participação não só na formação das individualidades, como também na maneira básica de cada um se relacionar, quer dizer, ao se defender que essa questão perpassa os diferentes patamares psicossociais, referimo-nos a uma espécie de padrão vincular, no qual, gestado a partir da família (grupo primário de socialização), tende a se repetir, posteriormente, em distintos agrupamentos de socialização secundária: grupo conjugal, grupo de formação escolar, de trabalho, etc. Desnecessário apontar que se,

vínculos, o curioso é que Bispo, ao longo dos anos, conquistou um espaço através de seus trabalhos com a arte (Escritos do Bispo, 1988; Hidalgo, 1996). 
de um lado, começamos o processo de socialização na família, de outro, seguindo o desenvolvimento, em tese, todos nós passaremos por outros grupos importantes, os quais não só rubricam e aprimoram tal experiência, como também são os referidos grupos de socialização secundária.

A segunda implicação básica, quanto à questão dos vínculos e sua relação com a autodestruição, refere-se ao fato de que existem dois tipos básicos de família: as de vinculação funcional (que têm um pendor para as relações estruturadas) e as de vinculação disfuncional (pendor para relações desestruturadas). $O$ curioso é que a diferença básica entre um grupo e outro não se firma pela inexistência de problemas, pois toda e qualquer família tem os seus; nem necessariamente se faz presente pelo rótulo de "família saudável" ou "família doente", já que não existe família totalmente saudável nem totalmente enferma; enfim, o que diferencia um tipo de família de outra é a forma peculiar em se lidar com seus particulares conflitos e distúrbios emocionais. Tal maneira própria, enfim, tem aqui um papel relevante no estudo em pauta, ou seja, é a partir disso que teremos um parâmetro básico para indicar se um grupo familiar difunde entre seus membros vinculações que tendem para a busca de relações mais estruturadas ou, ao contrário, para as relações menos estruturadas. Em outras palavras, as famílias de vinculação funcional se destacam como aquelas em que os membros tendem a se diferenciar, as de vinculação disfuncional, de outra parte, dizem respeito à situação em que seus membros tendem a se mostrar com dificuldades nessa área, ou seja, não se diferenciam. Tal dificuldade de diferenciação será desenvolvida aqui não só pelo entendimento de famílias simbióticas e esquizóides, como também, como veremos adiante, em muitos casos, poderá ter papel relevante em certas tentativas e até em alguns suicídios fatais (Bleger, 1984; Féres-Carneiro, 1996; Santos-Stubbe, 1995).

Em suma, essas são as questões importantes deste artigo e, para desenvolvê-las, ele será apresentado em quatro sessões básicas. Na primeira, visando a discussão da conceituação do suicídio, apresentaremos o debate através da sessão de título, "Suicidologia e os diferentes graus de autodestruição". Em seguida, visando a discutir o objeto pelo ponto de vista psicológico, teremos a segunda sessão:"Suicídio e o ponto de vista freudiano e junguiano". Na terceira, buscando problematizar o suicídio pelo "e", ou meIhor, pelo entrelaçamento da perspectiva psicológica e da social, teremos a sessão de título "Suicídio e processo psicossocial: uma leitura a partir do vínculo". Na quarta, apresentaremos a última sessão, que ressaltará as principais conclusões do artigo pela designação:"Reflexões conclusivas". 


\section{Suicidologia e os diferentes graus de autodestruição}

Durkheim (1971) defende que, mesmo supondo tratar-se de assunto aparentemente conhecido, não é das tarefas mais fáceis conceituar o suicídio. Dessa forma, nesta parte, vamos discutir tal conceituação e também algumas polêmicas em torno disso.

Em primeiro lugar, por exemplo, uma das grandes questões que se apresenta é demarcar o suicídio fora de posições preconceituosas, as quais Ihe dificultam o entendimento em termos terapêutico e preventivo, ou seja, nesse aspecto, nada pior do que algumas posições correntes que o designam, de um lado,"como um ato de coragem", de outro, "como um ato de covardia."Ora, adotar tal postura é ter uma atitude não só insustentável e preconceituosa como, também, totalmente inadequada em relação aos avanços do estudo desse objeto, seja do ponto de vista psicoterapêutico propriamente dito, seja do ponto de vista de entendê-lo teoricamente com vista a pesquisas para diminuir seus índices.

Em segundo lugar, em relação ao plano acadêmico, há dificuldades em termos de conceituá-lo de forma sistematizada, livre de quaisquer polêmicas. Dentre elas, destacamos: o suicídio é um evento que sua ocorrência, em geral, está relacionada a uma pluralidade de fatores²; o suicídio precisa ser estudado não só como uma questão que varia ao longo da história, como também, em termos de cultura, apresenta-se com diferentes significados; etc. Isso sem contar que, além disso, fica difícil precisar o que é de fato uma atitude destrutiva: por exemplo, podemos necessariamente caracterizar como suicida aquele que bebe ou o que fuma em excesso? Serão suicidas aqueles que contraem hábitos alimentares, os quais, inconscientemente, aumenta-Ihes significativamente a taxa de colesterol, induzindo-os ao infarto? E o que dizer dos que dirigem em alta velocidade e, às vezes, "até sem querer", encontram a morte em muitos acidentes de trânsito?

Frise-se que é em decorrência dessa e de outras polêmicas que cada escola faz um determinado recorte e o define a partir de seus pressupostos básicos: há o suicídio conceituado e defendido por uma escola sociológica, na qual se destaca o estudo de Durkheim (op. cit.), há o suicídio definido e estudado do ponto de vista da psicanálise, da psicologia analítica, da psicologia institucional e assim por diante.

Esse trabalho, baseando-se em Stubbe e Bojanovsky (1982), conceituará o suicídio como um acontecimento que é subscrito por uma tendência à autodestruição, na qual poderá ser discutido através de um contínuo existencial. A partir disso, diante de diferentes indivíduos, observa-se o se-

2 Analisando-o criticamente, observamos que, de um lado, o suicídio se relaciona com uma pluralidade de fatores, ou seja, em geral, suas causas têm ligações com fatores sociais, individuais, culturais, familiares, etc; de outro, independente disso, o suicídio tem seu lado singular, ou seja, diante de sua complexidade, ainda tendo a ver com uma pluralidade de fatores, dependendo do contexto, diante de sua emergência, pode ser que um deles prepondere sobre os demais. 
guinte: de um lado, se há aqueles que estão avançando e, na medida do possível, o fazem enfrentando os seus problemas cotidianos, de outro, ao contrário, existem os que, às vezes, tendo até condições sociais e econômicas melhores do que os primeiros, paradoxalmente, desistem de viver e procuram o suicídio. Em outros termos, de uma parte, em um dos extremos do contínuo, situa-se o instante em que o indivíduo está vivo, de outra, em outra extremidade, encontra-se o instante em que ele está firmemente determinado a se matar e tem êxito no seu intento. Aqui, como se observa, não existe o suicídio, mas suicídios, ou seja, pela análise do contínuo existencial da tendência para autodestruição, está-se tratando menos do suicídio e mais de suicídios, os quais são expressos principalmente através de diferentes gradações. Tais gradações, afora nos indicar o possível avanço desse quadro que vai de um extremo ao outro, denotam que existem três graus básicos do fenômeno: primeiros graus de autodestruvidade, graus intermediários e graus extremos da morte de si próprio (v. Figura 1).

Primeiros graus de autodestrutividade: encontram-se aqui os primeiros graus de suicídios, os quais são caracteristicamente inconscientes. Estamos falando de uma fase cujos graus, notadamente relacionados à esfera do inconsciente, somos todos portadores. Além disso, deriva-se daí outra conclusão importante: mesmo sendo portadores de componentes inconscientes de autodestrutividade, de outra feita, isso não quer dizer que necessariamente sejamos alguém que apresentará uma tentativa de suicídio ou que se matará concretamente. Obviamente, se apresentarmos um aumento progressivo dessa tendência e não a tratarmos devidamente, podemos até apresentar uma "tentativa de suicídio" ou mesmo nos tornarmos um "suicida fatal"; contudo, a simples constatação dos primeiros graus em si, que são inerentes a todos, não é condição sine qua non de que venhamos, com toda certeza, a nos matar.

$$
\begin{array}{ccc}
1^{\text {os }} \text { graus de } & 2^{\text {os }} \text { graus de } & 3^{\text {os }} \text { graus de } \\
\text { suicídios } & \text { suicídios } & \text { suicídios }
\end{array}
$$

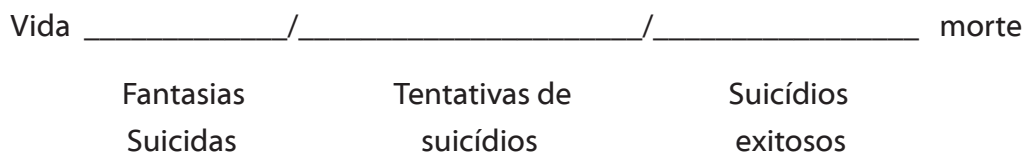

Figura 1. Contínuo da autodestruição.

Segundos graus de autodestrutividade: denotam os graus intermediários do acontecimento suicida. Nessa posição, há indícios concretos sobre esse acontecimento, ou seja, aqui, em termos mais diretos, realiza-se 
alguma atitude que põe em risco a sua própria vida: a pessoa apresenta a tentativa de suicídio.

Além de salientar que as tentativas de suicídio não se confundem com o suicídio fatal, afora denotar que as "tentativas" têm relação com os graus intermediários e o "suicídio de êxito" com os graus extremos ${ }^{3}$, destaque-se que nem todo paciente que tenta se matar necessariamente torna-se um suicida de fato. Mas, independente disso, sobretudo do ponto de vista terapêutico, frise-se que, diante de tal fenômeno, faz-se necessário dar-se aqui o devido valor para as tentativas. Essas não devem, de forma alguma, ser supervalorizadas e nem desvalorizadas, ou seja, entendê-las e acolhê-las verdadeiramente, como se vê, é a grande questão aqui. É importante prestar atenção nesse detalhe, quer dizer, caso negligenciemos esse fato - seja "colocando uma lente de aumento nas tentativas" ou se as "negarmos"-, há grandes riscos de que certos pacientes, ainda ambivalentes entre o desejo de viver ou de morrer, acabem infelizmente encontrando a própria morte.

Terceiros graus de autodestrutividade: situam-se aqui os graus extremos do comportamento suicida, os quais são traduzidos pelo instante através do qual a pessoa apresenta um forte e firme desejo de se matar. Nesse momento, todo cuidado é pouco, pois essa pessoa não só está firmemente determinada a se suicidar, como também há grandes probabilidades disso se concretizar. Se, diante dos graus intermediários, a pessoa em questão e a sua família devem buscar uma ajuda especializada, na última fase, mais do que nunca, é recomendável um trabalho de apoio multiprofissional (médico, psicólogo, terapeuta de família e do próprio agrupamento familiar para participar no processo), a fim de que se possa tentar reverter a tendência autodestrutiva. No último grau não devemos esquecer do seguinte fato: "O extremo da seqüência suicida são os suicídios consumados (fatais) que levam à morte" (Stubbe, 1995, p. 115).

Vindo ao encontro do ponto de vista do Contínuo da autodestruição, Carvalho (1996) defende que se pode caracterizar o paciente suicida de três maneiras fundamentais:a) em um primeiro grupo, há os que realmente desejam se suicidar. Nesse particular encontramos os que usam de um método seguro e é praticamente muito difícil tentar demovê-los dessa idéia, ou seja, estamos falando dos pacientes que se situam nos graus extremos de autocídio; b) existem aqueles que dizem que querem se matar e, felizmente, ao praticarem a tentativa de suicídio, fazem isso de uma maneira não tão contundente e precisa, quer dizer, encontramos nessa situação os pacientes que estão nos graus intermediários/graus das tentativas; c) por último, existem os que falam que querem morrer, pois não há mais sentido em existir, entretanto, esses não apresentam nenhuma tentativa direta, nem demonstram nenhum fato real, no aspecto de que não apresentam

3 A diferença básica das tentativas e do suicídio fatal, afora os distintos graus, é que nas "tentativas", mesmo buscando isso, há a preponderância de um desejo ambíguo; já na fase do suicídio fatal, tais pacientes não têm ambigüidades, ao contrário, eles estão firmemente determinados a buscar a morte de si mesmos (Stengel, 1969; Stierlin, 1978). 
nenhuma atitude concreta contra a sua própria vida. Em outras palavras, falamos aqui dos primeiros graus, ou dos graus inconscientes que podem avançar ou não em prol do suicídio, mas, nessa fase, é algo que se situa na esfera da fantasia inconsciente.

\section{Suicídio e o ponto de vista freudiano e junguiano}

\subsection{A perspectiva psicanalítica ${ }^{4}$}

Curiosamente, na obra freudiana, excetuando alguns textos, não há propriamente uma parte que trate diretamente do suicídio. De forma geral, existem diferentes textos que fazem referência sobre essa questão, como é o caso, por exemplo, de Contribuições para uma discussão acerca dos homossexuais e Luto e Melancolia (Freud, 1910/1988; 1917/1989). Tal fato não quer dizer que Freud tenha desconsiderado essa questão. Ao contrário, se lembrarmos que a psicanálise nos oferece grandes contribuições para o psiquismo, impossível afirmar que ela desconsidera totalmente o suicídio. O texto Sobre uma psicogênese de um caso de homossexualidade feminina (Freud, 1920/1975), entre outros, é uma das ilustrações pela qual Freud se manifesta a respeito. Nele, discute-se o caso de uma jovem que tenta o suicídio, logo após a intransigência dos pais frente às suas tendências homossexuais. Assim, independente de que cada caso apresente sua singularidade e muitas tentativas possam ser creditadas ao plano da mera manipulação, nessa parte de sua obra, Freud discute o suicídio de forma sui generis. Para ele, na realidade, a tentativa de suicídio da jovem foi realizada como um ato não só para punir-se, como também para concretizar um desejo inconsciente.

O desejo inconsciente referia-se ao seu objetivo de conseguir um filho com o pai, e este era um dos motivos pelos quais a moça optara pela homossexualidade, pois em sua fantasia isso a preservaria do risco de manter relações com seu progenitor... $\mathrm{O}$ aspecto autopunitivo relacionava-se ao desejo de morte que nutria contra o pai por não consentir que havia tido com o seu progenitor o filho que ela mesma desejava ter conseguido dele. (Faria, 1997, pp. 29-30)

Tal fato caminha ao encontro de uma das explicações básicas psicanalíticas sobre o suicídio, a qual, a partir de Freud, passa a ser defendida por alguns neofreudianos: ninguém mata a si próprio - diz um deles-, caso não queira matar também a um outro alguém (Fenichel, 1981). 
Enfim, quanto ao suicídio e a psicanálise, além dessas considerações sobre Freud, observa-se muitos pós-freudianos debatendo essa questão de maneira mais direta.Vejamos, a seguir, algumas dessas posições.

O suicídio e a identificação narcisista

Segundo Abadi (1973), a perda de um objeto libidinal valioso pode ser uma das grandes motivações para o suicídio. Desaparecer da vida é o forte desejo da pessoa em comportamento autodestrutivo, tal como desapareceu para ela o seu objeto amado. Em outras palavras, o desejo de pretensamente obter novamente o indivíduo querido que morreu, por exemplo, é tão intenso que diante da impossibilidade de recuperá-lo na realidade consensual, tal pessoa não só se identifica de forma extremamente narcisista com o objeto perdido, como também pode destruir-se para acompanhá-lo ou tê-lo de volta, em sua fantasia.

\section{O suicídio autoagressivo}

Uma outra posição psicanalítica sobre o suicídio diz respeito ao paciente deprimido. Nesse caso, quando o paciente tenta o suicídio, argumenta Fenichel (1981), ele está efetivamente voltando o sadismo de seu superego contra si, de forma que, infelizmente, pode até destruir a sua pessoa. Vendo de outro modo, o melancólico, ao voltar a agressão contra ele mesmo, na realidade, quer atacar um objeto exterior, mas por não consegui-lo, ocorre o pior, ou seja, na hipótese de a pessoa ser agredida pelo meio e não ser possível revidar tal agressão, tal pessoa retorna-a contra si própria. Nessa situação, lamentavelmente, há grandes riscos dela se matar, realizando, então, o denominado suicídio autoagressivo.

Pensando no suicídio autoagressivo em alguns deprimidos, nos quais, por detrás dessa sua autodestruição fatal, desvelava-se um desejo forte em matar alguém, assim, parafraseando o criador da psicanálise, poder-se-ia dizer que é exclusivamente esse sadismo que soluciona o enigma da tendência ao suicídio, tornando a melancolia tão intensa e perigosa, pois "ninguém mata a si próprio, sem antes querer matar um outro" (Freud, 1917/1989).

\subsection{A perspectiva junguiana: o suicídio e a alma}

Opondo-se a estudos exógenos sobre o suicídio que o reduzem apenas ao lado "de fora" do indivíduo e explicam todos os fenômenos humanos por "médias","desvio" e outros artigos do gênero, discutiremos a perspectiva junguiana. Aqui, diante do suicídio, se defende a metáfora do estudo da alma, a qual, além de ser uma leitura endógena, se opõem as quatro metáforas básicas de sustentação da realidade exógena. 
Antes de apresentarmos a questão da alma e a sua relação com o suicídio, ponto de suma importância para a perspectiva junguiana e para a sua leitura endógena, faz-se necessário discutirmos as quatro metáforas básicas que sustentam a leitura exógena ${ }^{5}$. Tais metáforas, que sustentam a leitura exógena e são uma espécie de alicerce da realidade social, são: a metáfora da sociologia, a metáfora do direito, a metáfora da teologia e a metáfora da medicina.

A existência dessas metáforas se sobressai porque elas não só dão sustentação à realidade social, mas também a defendem e a revalidam no dia-a-dia. Referimo-nos a uma realidade social que é diversificada aqui pelos seus principais modos, ou seja, pela sociologia, pelo direito, pela teologia e pela medicina. Em outras palavras, se a metáfora da sociologia existe para defender e revalidar a compreensão do agrupamento social, se a do direito para o conjunto de leis e normas do Estado e de suas organizações, a metáfora da teologia e a da medicina, por sua vez, ganham destaque não só porque a da primeira defende os pressupostos do pensamento religioso clássico, como, também, a da segunda, os da medicina clássica.

A título de ilustração, vejamos alguns exemplos: quanto à teologia, apesar de sua metáfora se basear no pressuposto explícito de que não se deve pôr em risco a vida, já que ela nos é dada por Deus e, portanto, só a Ele cabe retirá-la, independente disso, tal metáfora admite que há exceções frente a tal pressuposto. Quer dizer, mesmo diante da defesa incondicional da vida, que se baseia na assertiva do "não matarás", há casos que isso pode ser rompido, ou seja, essa regra pode ser rompida, desde que existam guerras, as quais poderão ser justas, se forem principalmente para defender a ordem em prol da "santa igreja" e do papa. Enfim, nessa posição, de acordo com Hillman (1993), o que está em questão, implicitamente falando, é menos a defesa da vida em sua total plenitude e mais os interesses corporativos, os quais se proliferam como uma espécie de "igrejismo", em prol da ordem institucional dessa metáfora.

Mas a defesa dos interesses corporativos não se reduz apenas à metáfora acima, mas se aplica na defesa dos interesses de todas as outras metáforas em discussão aqui. A metáfora da medicina, por exemplo, que se posiciona explicitamente pela preservação da vida, argumentando que cabe ao médico defendê-la sob quaisquer hipóteses, ainda que se pesem as boas intenções, há aqui um fato espantoso. Tal defesa está apoiada em uma noção de saúde quantitativa, a qual pretende subscrevê-la exclusiva-

5 O estudo endógeno é aquele que vê a questão do suicídio apenas pelo lado da dita realidade objetiva. Esse, além de se referir ao considerado lado de "fora" dessa questão, é sinônimo aqui da realidade social. Nesse aspecto, faz-se estudos sobre o suicídio de forma sistematizada por "médias", por levantamentos estatísticos e assim por diante. Embora tenham a sua importância, tais estudos não atendem a perspectiva junguiana porque não consideram o suicídio pelo seu lado da singularidade. Essa é defendida por tal perspectiva porque se trata de um dos fatores cabais na análise do comportamento autodestrutivo: o "lado interno", ou melhor, o lado da singularidade, uma vez observado, poderá nos desvelar a ordem simbólica e inconsciente no suicídio. Daí ser denominado lado da realidade extra-social ou psíquica. 
mente só no combate à doença. Em outras palavras, aqui se observa a defesa de uma saúde que se reduz apenas à preservação do corpo biológico, já que não só é objeto "científico" da medicina clássica, como também toda e qualquer variável que escape a isso é taxada de questão subjetiva, um conhecimento dito menor. Ora, na realidade, ao se fazer a defesa da saúde ao mero combate à doença, ao se reduzir essa saúde apenas à preocupação com o corpo biológico, longe de se estar a favor exclusivamente do interesse da ciência e da existência sob seus vários ângulos, se está fazendo a defesa implícita dos interesses da corporação clássica da medicina ${ }^{6}$.

Curiosamente, essas metáforas defendem seus interesses em nome de uma ordem social, combatendo com todas as forças qualquer fator que ponha em risco tal fato. Dentre esses fatores, o suicídio ganha destaque, na medida em que todas as quatro metáforas o enxergam como algo que afronta isso; assim. elas dizem combatê-lo veementemente. Entretanto, há nesse procedimento uma contradição: embora se digam contra o suicídio, ao exercerem a forte tendência mais a favor de interesses corporativos e de seus grupos institucionais e não da existência em suas várias manifestações, tais metáforas acabam também combatendo a possibilidade de manifestação de uma singularidade que não está de acordo com o padrão grupal exigido pelos seus interesses corporativos; então, paradoxalmente, essas metáforas acabam reunindo condições para que a morte de si mesmo possa aumentar. Como assim? Ora, ao se fecharem para o entendimento de que muitos desses atos suicidas tendem a ocorrer, notadamente, porque falam de um processo singular (singular, sobretudo, em relação ao modelo que pregam), ao não perceberem que muitos dos casos da morte de si próprio podem ser uma espécie de linha de fuga "individual" frente a muitos interesses institucionais e corporativos, essas quatro metáforas, talvez até de modo inconsciente, podem estar virando as costas para um fator importante na questão da autodestruição e, por consequência, contribuindo para que os índices possam aumentar?

É notadamente por esses e outros argumentos que a perspectiva junguiana se opõe a se discutir os suicídios apenas pelo ponto de vista exógeno. Vendo de outro modo, diante de tal quadro, como se observa, as metáforas do direito, da medicina, da teologia, da sociologia, além de estarem defendendo o seu território institucional, apontam para um ponto

6 Como o objetivo aqui é desenvolver a perspectiva junguiana e o estudo da alma, sugere-se que não só se desenvolvam pesquisas sobre as instituições sociais e o suicídio, mas também que se aguarde a conclusão de outra pesquisa que desenvolvemos, a qual deverá ser publicada com o título:"As instituições sociais e o suicídio: um estudo por diferentes modos de subjetividade".

7 Criticando as metáforas sociais, esse artigo não é a favor do suicídio, nem é contra a sociologia, a teologia, o direito e a medicina. Ora, lançando mão de algumas reflexões, apenas estamos problematizando que essas metáforas, mesmo tendo seu papel, deixem de defender exclusivamente o agrupamento social, seus interesses corporativos em detrimento da singularidade. Nunca é demais dizer que, contraditoriamente, não dando crédito à singularidade, essas metáforas podem estar colaborando para o aumento do suicídio. 
em comum: tais metáforas eliminam a possibilidade de se ver e discutir a morte - e inclusive a morte de si mesmo - como algo que tem a ver com a singularidade, com a alma.

Os modelos a partir dos quais esses quatro campos mais relacionados com o suicídio encaram o problema não são de nenhuma ajuda para o analista. Todos eles julgam o suicídio de maneira preconceituosa, em parte porque o suicídio ameaça as metáforas básicas que eles se apoiam.Por isso,todos eles compartilham certos traços comuns. A principal preocupação é com a prevenção do suicídio, porque os modelos estão impregnados de um terror da morte. Esse terror advém do fato de não terem, no estado atual de seus modelos de pensamento, um lugar adequado para a morte. Concebem a morte como exógena à vida, não como algo que reside na alma, não como uma possibilidade e uma escolha contínua. Admitindo isto, estariam admitindo o suicídio, dessa maneira ameaçando suas próprias fundações. Nada estaria seguro, então, nem a Sociedade, nem a Lei , nem a Igreja, nem a vida. (Hillman, 1993, p. 46) ${ }^{8}$

\section{A metáfora da alma: da literalidade ao suicídio simbólico}

Para a perspectiva junguiana, o suicídio deve ser estudado pelo seu lado de singularidade, ou seja, se há aqueles que o estudam pelo seu aspecto de "fora", o qual é um fato que foi discutido pelas quatro metáforas acima, o analista junguiano deve vê-lo pelo seu lado de "dentro", ou melhor, pelo lado de sua alma. Isso implica que tal lado se destaca pela sua riqueza simbólica e também porque desvela principalmente o significado do ato suicida. Em outras palavras, a metáfora básica da alma, acima de tudo, fala da busca do significado que existe na singularidade de cada ato humano e, especialmente, no do suicídio. Quando se diz que não se trata de sermos a favor do suicídio, mas sim de compreender o que isso significa para a alma, estamos enxergando que há diferenças entre o suicídio visto de uma forma literal e de uma que se desvele o seu significado pela compreensão da psique. Na realidade, aqui o estudo do significado é uma busca que nos fala da alma e também de um registro singular que há por detrás de todo e qualquer comportamento que o indivíduo manifesta no mundo externo; entretanto, especificamente, no caso em questão, trata-se da busca do significado simbólico do suicídio, o qual tem relação, principalmente, com seu lado "de interioridade".

Como nem sempre a exterioridade, de acordo com Jung, corresponde pura e simplesmente à interioridade, caberá ao analista, antes de tudo, procurar a manifestação da alma, em seus distintos significados. Nunca é

8 Afora o preconceito com a morte, analisando o discurso dessas metáforas, há aqui brechas que podem ser debatidas pela análise institucional, pois denunciam uma questão corporativa. Como agora estamos debatendo a perspectiva junguiana, para aprofundar isso, entre outras, sugere-se a leitura: Bastos (2001). 
demais sinalizar que isso se traduz pela busca do lado "de dentro" em cada ato e em cada indivíduo que se encontra em processo de análise.

A preocupação de um analista é manter sua conexão com o interior e não perder sua metáfora básica (metáfora da alma). Senão, ele começa a ver seus pacientes como exemplos de categorias e começa a se ocupar em resolver a delinquência, a psicopatia, a homossexualidade e assim por diante, ao passo que seu chamado é atender a alma dos indivíduos que exibem traços típicos em seu comportamento externo. A tipicidade exterior não significa uma similaridade correspondente de experiência. Os "alcoólatras" os "delinquentes",os "psicopatas" não experimentam suas formas típicas de comportamento da mesma maneira. A intencionalidade das ações difere em pessoas diversas. A literatura sobre suicídio..., mostra uma variedade exaustiva de circunstâncias e propósitos, que não correspondem às formas típicas de comportamento externo chamados suicídios por afogamento ou suicídio depressivo ou suicídios sob estado de desequilíbrio mental.(Hillman, 1993, pp. 54-55)

O"lado de dentro", além de ser visto como uma disponibilidade para se desvelar o significado dos acontecimentos que são vividos pelo cliente, relaciona-se ainda com uma espécie de experimentar, compreender e, de certa forma, compartilhar do sofrimento e da experiência que nos é narrada na análise, só que de uma maneira singular e acolhedora, fato que pode ser desenvolvido no processo psicoterapêutico da psicologia analítica. Isso é totalmente diferente de um tipo de ciência clássica que vê o paciente como portador de um sintoma, no qual o mais importante é descrevê-lo, catalogá-lo dentro dessa ou daquela nosologia. Fazer tal procedimento é objetivar o estudo do "lado de fora".

Em relação ao suicídio, por exemplo, podemos observar que estudálo é nos depararmos basicamente com duas psicologias: há a psicologia do suicida que o estuda e o percebe pelo "lado de fora" e a psicologia que o vê como uma problemática pelo "lado de dentro".Enquanto a primeira, em geral, tende a vê-lo por um discurso que quase não considera o significado do ato, a segunda não só faz tal consideração como também pode nos oferecer uma esteira rica desses significados a fim de que possamos entendêlo melhor pela metáfora da alma9.

Como não é nosso objetivo aqui desenvolver a perspectiva junguiana em sua total acepção propriamente dita, mas o seu ponto de vista sobre o suicídio, a seguir ressaltaremos os pontos principais que tal posição sugere na compreensão do fenômeno em discussão. Em síntese, eles são: (10) $O$ paciente suicida deve ser acolhido na análise não como um conceito, e sim como um indivíduo, ou seja, aqui se devem fazer todos os esforços por entender e acolher a história de vida do cliente que é uma singularidade em

9 Vindo ao encontro da perspectiva junguiana, em um estudo sobre o desemprego e o suicídio, Ludermir (1994) aponta que apesar de o desemprego ser um fator relevante, não há uma correlação direta entre tais fatores; entretanto, nesse particular, faz-se mister a questão da singularidade. 
processo e também um indivíduo cuja morte está em jogo; (2) é a partir disso (acolhimento como pessoa e estudo de sua história de vida) que teremos chances de ver o paciente como um todo e também de desvelarmos qual é a fantasia mítica, a qual, talvez, esteja sendo encenada em relação ao suicídio. Diante da morte de si próprio, enquanto não adentrarmos na fantasia do sujeito sobre isso, todas as nossas ações e até as nossas atitudes terapêuticas serão praticamente como "letras mortas", ou seja, não irão além da superfície. Enfim, agindo apenas pela periferia ou superfície, dificilmente entenderemos essa singularidade de alma nesse acontecimento; $\left(3^{\circ}\right)$ para desvelar essa fantasia mítica e penetrar no "lado de dentro", além de salientar o papel vital do analista nesse processo de desvelar a alma, ele necessariamente tem que atuar como espelho. Espelho, aqui, quer dizer que o analista funcionará não só como aquele que acolhe o cliente, compartilha de alguns sofrimentos de forma terapêutica, mas também, e principalmente, trabalha com o suicida de maneira que mantém um "pé dentro" e um "pé fora" da fantasia do cliente em questão. Tal procedimento necessita ser realizado, notadamente, para que se entenda a fantasia do suicida e também para desvelá-la em sua cadeia de significados. Atuar como espelho é não só revelar essa cadeia de significados, mas também, na relação, buscar uma forma de expressão - seja na arte, seja através de outro dispositivo. Tal busca é muito importante, pois ajudará o paciente a reverter essa tendência de destruição; $\left(4^{\circ}\right)$ o estudo do suicídio junto à alma, antes de tudo, tem a ver com o desvelar de um arquétipo que tem papel relevante nesse comportamento. Desvelando-o, não só perceberemos algo que se relaciona com traços simbólicos e com o inconsciente coletivo como também tem importância cabal na subscrição da autodestrutividade, ou seja, com isso perceberemos que há algumas pessoas que trazem simbolicamente uma tendência forte para a morte de si próprias. Isso, ao ser entendido dentro do processo de análise, com apoio devido, ajudará o cliente a perceber o suicídio menos do seu aspecto literal e mais do aspecto simbólico, aumentando-lhe as chances de não confundir uma realidade com a outra, diminuindo-lhe as probabilidades de se matar concretamente na realidade consensual. Ora, percebendo tal fato teremos maiores possibilidades de acolhermos os pacientes portadores do problema do suicídio, fornecendo-lhes continente para que se manifestem sem temor sobre suas "viagen pela fantasia da morte",as quais, em tese, têm a ver com "suas histórias de vida"; $\left(5^{\circ}\right)$ uma vez estudado o arquétipo e a singular fantasia de morte, o paciente começa a se deparar com o momento de ter um encontro verdadeiro com ele mesmo, ou seja, aqui, na maior parte das vezes, caminha-se em direção ao processo de individuação.

Tal processo trata principalmente do autoaprimoramento, ou meIhor, para os pacientes que são portadores da vivência traumática do suicídio, em síntese, isso significa basicamente: em primeiro lugar, essa vivência aponta que do ponto de vista simbólico, o paciente precisa deixar morrer 
alguns lados seus, os quais não comportam mais existir com ele mesmo. Em segundo lugar, a partir da experiência traumática em questão, por mais dolorosa que seja, ela é também a oportunidade de se deparar com o processo de individuação que pode Ihe modificar a sua opção de vida e de estrutura, vamos dizer assim. Estamos falando do contato com o lado do "Eu-maior", da iluminação interior, do encontro com nosso verdadeiro eu que habita na alma de cada um. Desnecessário afirmar que, para a perspectiva junguiana, todos, sem exceção, temos esse lado dentro de nós e precisamos desenvolver a busca desse processo.

O processo de individuação, além de ser considerando por alguns autores a preparação para o desvelar da morte em nós, em termos de entrarmos em contato com o que há de mais verdadeiro em cada um (Jaffé, 1995), denota-se pela busca da integração de vários aspectos de nossa personalidade, tal como animas e anima, a sombra e o nosso Eu-maior. Enfim,é o encontro com o Luminoso em nós, ou o Divino que há dentro de todo ser humano, fato de grande importância para o processo analítico. Ora, ao tomar contato com isso, na análise, o paciente pode desenvolver-se de forma totalmente diversa ao sentido de sua vida e sobre o fenômeno de autodestruição que apresentava até então.

\section{Suicídio e processo psicossocial: uma leitura a partir do vínculo}

Discutiremos agora a possível relação entre o suicídio e o agrupamento social, ou seja, traremos à baila autores que pensam esse entrelaçamento, no qual, uma vez entendido, traz contribuições no plano da prevenção e da terapia ao suicídio. Nesse sentido, dentre eles, destacaremos especialmente a perspectiva de Bleger. Esse não só nos dará elementos para problematizar esse entrelaçamento como também o ressaltará particularmente pela questão do vínculo. Tal questão inicia sua análise a partir das relações primárias ou relações familiares ${ }^{10}$.

Bleger será debatido aqui através de três pontos básicos: 3.1- Bleger e o processo psicossocial; 3.2- Processo psicossocial e relações sincréticas e não-sincréticas; 3.3-Tipos básicos das famílias e"ego sincrético" e"ego estruturado".

10 Hendi, entre outros exemplos, é um outro estudioso que também se sobressai nesse entrelaçamento apontando um " $\mathrm{e}$ " ou um "entre" existente na vida pessoal e coletiva, no caso a partir de estudos sobre o suicídio junto à Dinamarca, Suécia e Noruega. Em outras palavras, além de Bleger, tal estudioso discute a autodestruição fatal como a que se relaciona com o contexto psicossocial, predominantemente se desvelando pela análise da interação das atitudes sociais e da psicodinâmica das relações familiares (Hendi, 1964; Ramos, 1974). 


\subsection{Bleger e o processo psicossocial}

Bleger (1984) argumenta que um dos equívocos básicos da psicologia é ler os diferentes problemas humanos apenas pelo âmbito individual. Ainda que do ponto de vista clássico tal objeto possa ser definido como o estudo da observação do dito comportamento individual, entendê-lo desconsiderando outras questões que estão aí implicadas, na realidade, é realizar um reducionismo crasso. Contrapondo-se, defende que os problemas humanos devem ser decodificados, através de um quadro de compreensão psicossocial, que se apresenta por quatro níveis básicos: $\left(1^{\circ}\right)$ compreensão do nível individual; $\left(2^{\circ}\right)$ compreensão do nível das inter-relações (que têm seu início nas relações familiares); $\left(3^{\circ}\right)$ compreensão do nível da instituição; $\left.4^{\circ}\right)$ compreensão do nível da sociedade como um todo, ou do sistema social e histórico. A título de ilustração, sugere-se que se observe a (Figura 2).

O quadro do psicossocial de Bleger implica principalmente que diante de distintos problemas humanos, dentre os quais o suicídio se sobressai, tal fenômeno necessita ser compreendido de uma forma diversa à percepção corrente, a qual, em geral, é defendida pela psicologia clássica. Em vez de se ler esse fenômeno exclusivamente pela ótica do dito individual, urge percebê-lo também por outras razões que transcendem isso. Em outras palavras, pela leitura do modelo psicossocial de Bleger se percebe que diante dos intrigantes problemas humanos, existem dois tipos básicos de compreensão: a) a leitura pelo modelo individualista; b) a leitura pelo modelo psicossocial.Vejamos, a seguir, o que tal fato significa.

De 4 para 1 (âmbito do modelo psicológico e social)

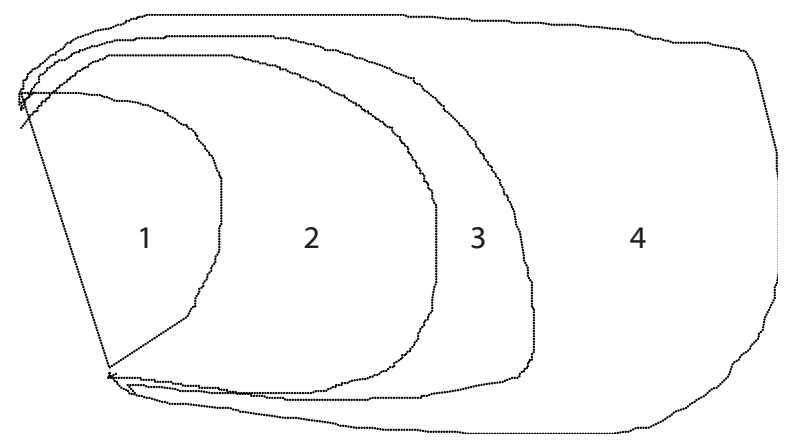

Figura 2. Quadro do Modelo Psicossocial. Reproduzida de Bleger, 1984, p. 34.

De 1 para 4 (âmbito do modelo individual) 1 = Território individual; 2 = Território inter-relacional (que parte da família); 3 = Território das instituições; 4 = Território do social, da sociedade como um todo. 
a) A leitura pelo modelo individualista ("de 1 para 4"): em tese, tratase de uma leitura pela qual, a priori, já se "culpa" o sujeito e sua "alma" pela causa desse acontecimento, ou seja, por tal perspectiva se explica exclusivamente o suicídio por questões individuais, virando-se as costas para compreensões diversas que transcendem a isso. Nesse particular, a princípio negamos que se possa pensar tal acontecimento junto às questões inter-relacionais, institucionais ou sociais, inclusive do seu aspecto macropolítico. Enfim, estamos falando de uma leitura que, além de ser feita "de 1 para 4", privilegia a explicação de um “EU", ou de um modelo individual, que se sobrepõe a todo e qualquer outro fator na explicação do suicídio.

b) A leitura pelo modelo psicossocial ("de 4 para 1"): em geral, tratase da leitura através da qual, diante do autocídio, quer-se debatê-lo junto à sociedade como um todo, notadamente desvelando-o pelo prisma de inter-relações que se dão em vários níveis. Tal fato implica que diante do suicídio, esse precisa ser analisado junto de relações psicossociais, com suas implicações em seus diferentes segmentos. Em outras palavras, nesse particular, ao se defender que o suicídio tem a ver com uma pluralidade de fatores, diante de sua ocorrência, ele deve ser discutido não só por questões individuais, mas também por suas repercussões em termos institucionais, em termos inter-relacionais e em termos históricos, para ficar em alguns exemplos.

Cabem ainda aqui dois comentários: em primeiro lugar, mesmo que se defenda que o suicídio precisa ser analisado por essa pluralidade de fatores, ainda assim não se está necessariamente descartando o componente individual nesse fenômeno. Em segundo lugar, nunca é demais ressaltar que a questão do suicídio não deve ser analisada pela ótica do a priori, quer dizer, ele não dever ser visto por explicações que querem reduzi-lo apenas a perspectiva individual ou a qualquer outra. Para evitar esse e outros disparates, os quais, na realidade, promovem uma visão preconcebida e simplista, é recomendável que analisemos o suicídio e sua eventual ocorrência não só pelo prisma do modelo psicossocial citado, como também - e principalmente - a partir de cada contexto. Dessa forma, diante de um caso de suicídio, por exemplo, ao analisarmos seu particular contexto, talvez o lado institucional esteja preponderando sobre os demais; de outra parte, em outro caso, talvez o contexto acabe nos indicando que, agora, prepondere o lado individual e assim por diante.

\subsection{Processo psicossocial e relações sincréticas e não-sincréticas}

Analisando a autodestruição junto ao esquema psicossocial podemos nos indagar sobre as causas estruturais do suicídio. Tal questão agora será debatida, a partir da apresentação e discussão das relações sincréticas e não-sincréticas. 
Discutindo os problemas humanos pelos agrupamentos, a partir desse modelo de compreensão, Bleger ainda nos chama a atenção para que se faça uma psico-higiene em um ponto que é vital e determinante para estarmos no mundo. Tal psico-higiene, na verdade, significa basicamente a promoção de uma espécie de trabalho em nossas relações. Além de precisarem ser repensadas, o trabalho sobre essas relações deve ocorrer em prol de uma espécie de saúde mental nesses inter-relacionamentos pelos distintos grupos sociais.

Qual o porquê de implementarmos a psico-higiene, ou melhor, um repensar das relações pelos diferentes grupos? Segundo o autor, em tese, os grupos se mostram por relações de dois tipos básicos: $\left(1^{\mathrm{a}}\right)$ relações desestruturadas - que têm um pendor para relacionamentos que não aprendem a se diferenciar, ou seja, de um lado, apresenta-se por relações exacerbadamente "abafadoras" (quando os membros de um grupo tendem a se misturar extremamente entre si), de outro, por relações com pendor exacerbadamente individualistas (membros que, talvez com receio de se misturaram, desenvolvem a tendência oposta, no aspecto de se evitar ao máximo a interação com o outro); ( $2^{a}$ ) relações estruturadas - há aqui um pendor para relacionamentos diversos às relações do ponto acima, ou seja, nesse particular, as pessoas aprendem não só a respeitar a individualidade de cada membro do grupo como, também, quando necessário, aprendem a desenvolver tarefas em grupo, realizando então o processo de diferenciação, o qual, de acordo com as teorias da área (Féres-Carneiro, 1996), é sinônimo das relações com tendência para a estruturação. Tais relações se denotam por aquelas que apresentam parâmetros mínimos de que as pessoas demonstram que aprenderam a "saber ser nós" (realizar tarefas em grupo) e a "saber ser eu" (realizar tais tarefas sem desconsiderar as diferentes individualidades). Em outras palavras, as relações que se apresentam com tendência para vínculos desestruturados, ou que apresentam problemas no plano da diferenciação, são as que podem ser designadas por relações sincréticas; as relações com pendor para as estruturadas, no caso, são as relações não-sincréticas ${ }^{11}$.

A proposta de se implementar uma psico-higiene nos grupos, a partir da família, se insere aqui, ou seja, como a dificuldade de diferenciação denota-se principalmente na dependência em excesso entre seus membros, na pouca autonomia, na baixa autoestima e assim por diante, como esses e outros fatores do gênero tendem a se traduzir por enormes dificuldades nos relacionamentos, em muitos casos, essas dificuldades são também atuadas através das tentativas de suicídio ou mesmo em suicídios fatais.

11 Sobre a definição acerca do que é saúde ou doença mental, nesse particular Bleger partilha da perspectiva da teoria familiar da comunicação, que diz: não existem vinculações totalmente saudáveis nem totalmente enfermas; entretanto, há relações que tendem para interações mais saudáveis ou para mais enfermas, ou seja, o que faz com que algumas relações apontem mais para um tipo de relacionamento ou para o outro é a construção, a partir da família, de vínculos não sincréticos ou sincréticos. 
Enfim, notadamente, em função disso, de acordo com Bleger, é que se faz presente a necessidade de se repensar essas relações, ou a implementação da psico-higiene, a partir das famílias. Evidentemente que a psico-higiene busca promover um repensar a favor das relações não sincréticas em detrimento das sincréticas.

A fim de entendermos melhor tal fator e principalmente a questão vincular, a qual é gerada a partir da família, sugere-se que se observe o ponto seguinte.

\subsection{Tipos básicos das famílias e "ego sincrético" $e$ "ego} estruturado"

Para estudar o suicídio, da análise psicossocial e pelo problema da diferenciação, discutiremos a sua relação com o grupo familiar (agrupamento primário de socialização). Esse não só é o ponto de partida através do qual se gesta o padrão básico de vinculação como também é através dele que se começa a formar o "ego sincrético" ou o"ego estruturado", fatores de suma importância nessa discussão.

Antes dessa discussão, vale acentuar que se o padrão vincular básico é gerado na família, após tal fase, em termos do desenvolvimento, o indivíduo prossegue em sua socialização por outros grupos importantes. $O$ curioso é que afora prosseguir esse desenvolvimento pelos agrupamentos de socialização secundária (grupo da instituição de educação, da instituição de trabalho, de cônjuge, etc), independente de aprendermos na família um padrão de relação que pode ter um pendor para vinculações mais"saudáveis" ou não, diante dos grupos de socialização secundária esse padrão vincular tenderá a se repetir. Tal fato, por sua vez, acarretará uma série de problemas e, às vezes, até as tentativas de suicídio e o suicídio fatal, com já foi sinalizado. Não é à toa que dada a sua relevância, a interação ou a vinculação, para esse trabalho, ganha destaque, pois, além de se iniciar no grupo familiar, é a questão que perpassa os quatro níveis psicossociais (v. Figura 2).

Dentro das idéias principais de Bleger e de sua relação com o suicídio, vemos que há dois tipos básicos de famílias: famílias simbióticas e famílias esquizoides. As primeiras mostram-se por uma maneira peculiar de se relacionar, ou seja, a partir de suas inter-relações, não só os membros do grupo familiar aprendem um padrão vincular simbiótico, como também apresentam uma série de problemas, caracterizados basicamente, entre outros fatos, da seguinte forma: afora não conseguir demonstrar seu potencial criativo, tal família não consegue desenvolver suas tarefas, exceto se as realizam sempre em grupo; além de apresentar baixa autonomia e pouca autoestima, seus diferentes componentes tendem para a constante 
anulação do lado individual e se apresentam com elevado grau de dependência entre si. Isso sem contar ainda que os membros desse grupo não sabem respeitar os limites e nem apresentá-los de forma clara; toda e qualquer mudança, bem como os conflitos e as opiniões diferentes, são sempre vistos como algo que os ameaça e assim por diante. Em outras palavras, trata-se de famílias em que seus membros demonstram elevado grau de indiferenciação, fato que tem relação com o padrão vincular de "grude", elaborado a partir da convivência familiar.

As famílias esquizoides, por sua vez, destacam-se por ter membros que demonstram ser extremamente individualistas. Em geral, tais membros não estão disponíveis para que se estabeleçam proximidades afetivas, fato que lhes faz ficar cada vez mais isolados uns dos outros. Ora, esse sentimento de isolamento exacerbado entre as pessoas desse grupo denotase por uma grande dificuldade em interagir e em realizar qualquer tarefa coletiva. Vendo de outro modo, as famílias esquizoides são as que não só se apresentam por relações ultraindividualistas como também desenvolvem um pendor para que reine um espírito de "cada um por si e Deus contra todos", pouco se preocupando com uma série de problemas que isso acarretará.

Em suma, se a família simbiótica é aquela que promove muito "grude" entre os seus componentes cujos, vínculos se mostram pelo pendor de busca de extrema proximidade e também pelo sentimento preponderante de "abafamento" do outro; a família esquizoide, por sua vez, se caracteriza por vínculos extremamente individualistas, de maneira que se observa muita distância efetiva e afetiva entre os demais membros, ou seja, nessa última modalidade, tentando se defender desse sentimento de "anulação da individualidade", que se dá em nome da coesão grupal, inconscientemente, esses membros tendem a se isolar de forma exacerbada e acabam eliminando a possibilidade qualquer de trabalho ou de troca em grupo. (A título de ilustração, sugere-se que, a seguir, se observe a Figura 3).

Famílias
esquizoides
Famílias

simbióticas

Figura 3. Tipos básicos de famílias.

Para se compreender os tipos básicos de família e o problema da diferenciação, é preciso observar a relação disso com a formação do ego estruturado (ego não-sincrético) e do ego sincrético. Em outras palavras, o primeiro se refere às interações com um pendor para as "relações ditas saudáveis", quer dizer, isso significa aqui que se mostram por relacionamentos nos quais os demais membros do grupo familiar aprendem preponde- 
rantemente a se diferenciar. A formação do "ego-sincrético", de outro lado, denota-se por vínculos que o desestruturam, pois há aqui o predomínio de interações cujos membros se mostram indiferenciados, acarretando sérios problemas nos relacionamentos. Assim, seja na família simbiótica, seja na família esquizóide, há o predomínio de interações sob a égide do "ego sincrético".

Um parêntese: além de estar embasado na teoria institucional, o ponto de vista de Bleger se apoia em outras disciplinas, quer dizer, quanto ao conceito de "ego sincrético" e "ego não sincrético", especificamente, ele se inspira em uma leitura da psicanálise. Em outras palavras, tal leitura aponta que em termos de nosso desenvolvimento, todos nós passamos por um período de indiferenciação, o qual ocorre na infância, a partir da relação que estabelecemos com o "corpo" ou o vínculo com a função de mãe. Ora, diante disso, se há aqueles que, com todos os problemas daí decorrentes, conseguem superar razoavelmente essa fase e se diferenciam de forma estruturada, infelizmente há um outro conjunto de pessoas que nem sempre consegue superar tal fase. Esse último grupo pode ser entendido da seguinte forma: de um lado, trata-se de indivíduos que se misturam extremamente a esse vínculo materno e, de forma inconsciente, não só não conseguem se "desgrudar" do mesmo como também se gesta daí um pendor para a vinculação simbiótica; de outra parte, em face do mesmo relacionamento, o contrário também ocorre, ou seja, vemos aqui indivíduos nos quais, também de forma inconsciente, diante do medo de ficarem "colados" a esse vínculo significativo, desenvolvem um sentimento de isolamento extremado e se apresentam por vinculações esquizoides (Bleger, 1977).

Enfim, a partir dessa argumentação que, entre outros problemas, nos chama a atenção para a questão de vinculação e da indiferenciação, pode-se dizer também que essa questão é relevante em muitos casos de autodestruição. Pesquisas indicam que, de um lado, podem ocorrer tentativas de suicídios quando alguns indivíduos vivenciam a situação simbiótica, diante da qual, às vezes, querendo se diferenciar, infelizmente alguns jovens tentam o suicídio e até se matam (Cassorla, 1981). De outro lado, há pesquisas ainda discutindo a questão da dificuldade de diferenciação, só que pelo viés de vínculos extremamente esquizoides, quem sabe buscando sua inclusão em uma "pretensa exclusão afetiva" em que tanto o meio como elas próprias criam para si mesmas. As pessoas desse último estudo, o qual foi realizado com empregadas domésticas, tentam o suicídio e algumas chegam ao suicídio fatal (Santos-Stubbe, 1995) ${ }^{12}$.

12 Ainda sendo relevante na área de suicidologia, a questão de vinculação destaca-se em outras áreas. Dentre elas, pesquisando-a junto aos internos da FEBEM-SP, Guirado (2004) constata que, nesse território, muitos comportamentos considerados desviantes podem ser discutidos também pelo vínculo de abandono. 


\section{Reflexões conclusivas}

4.1. Uma das primeiras reflexões conclusivas é a de que não existe o suicídio, mas suicídios, ou seja, considerando que há fantasias inconscientes de suicídios, há atitudes ambivalentes entre a vida e a morte e existem suicídios de fato, então, o artigo destacou que a autodestruição pode ser compreendida por um contínuo que se apresenta por diferentes graus: há os primeiro graus de suicídio, que se relacionam aos graus inconscientes de autodestruição; há os graus intermediários, denotando-se por uma fase na qual se apresentam as tentativas de suicídio; existem os graus extremos: nesse instante, o paciente se apresenta firmemente determinado a se destruir. Aqui, mais do que nunca, do ponto de vista da prevenção e da terapia, há que se tomar muito cuidado em tal fase (v. sessão primeira:"Suicidologia e os diferentes graus de suicídio").

4.2. Além de estar relacionado a uma pluralidade de fatores, ainda sem desmerecer a singularidade do ato, o suicídio pode ser pensando a partir do esquema psicossocial de Bleger, o qual, diante da ocorrência de tal fator, propõe analisá-lo por seus distintos patamares. Em resumo, esses patamares básicos são: o patamar do território individual; o patamar do território inter-relacional, que é muito importante destacar que se inicia na família; o território do patamar institucional; o território da sociedade geral ou do fator sócio-histórico (v. sessão terceira:"Suicídio e processo psicossocial: uma leitura a partir do vínculo"). Entre outros fatos, a presente reflexão quer destacar que o suicídio, analisado assim, não só tem a ver com uma pluralidade de fatores (fatores sociais, institucionais, familiares, individuais), como também, em função de cada contexto, um desses pode se destacar sobre os demais. Por exemplo, digamos que ao se analisar um particular contexto, o fator social prepondere sobre os demais; em função de outro, pode ser que seja o fator pessoal e assim por diante.

4.3. Esse artigo chama a atenção ainda para o fato de que o que perpassa cada um desses patamares, em tese, é a questão vincular.Tal questão, além de ser gestada a partir da família (grupo de socialização primária), tende a se reproduzir nos outros diferentes grupos na posterior socialização (socialização secundária): grupo de formação escolar, grupo de trabaIho, grupo religioso, grupo conjugal, etc. Quando há sérias dificuldades no estabelecimento de vinculações, que o artigo denominou de vinculações sincréticas, em geral, isso se relaciona com o fato de que os indivíduos envolvidos provêm de dois tipos básicos de famílias, as quais apresentam problemas no processo de diferenciação: famílias simbióticas (que tendem a desenvolver vinculações de extrema proximidade ou "grude") ou famílias esquizoides (tendendo a desenvolver relações nas quais os membros são extremamente individualistas). Ora, de acordo com a análise psicossocial aqui discutida, diante desse quadro, quando os membros dessas famílias apreendem esse padrão vincular sincrético, até sem querer, tendem a 
repeti-lo nos outros grupos de socialização secundária, acarretando uma série de problemas no relacionamento, quer dizer, seja apresentando relações de muita dependência emocional (um dos fatores decorrentes da simbiose), seja se mostrando com enormes dificuldades em interagirem e em desenvolver qualquer tarefa em grupo (um dos problemas que se relacionam com a esquizoide), tais indivíduos ficam impedidos de se expandir plenamente. Enfim, em decorrência disso, há muitos pacientes que às vezes tentam o suicídio e até realizam o suicídio fatal.

4.4. Afora a questão dos vínculos, outro ponto para o qual o artigo chamou a atenção é sobre a questão de algumas das principais instituições sociais e o suicídio. Tais instituições, principalmente quando sustentadas em metáforas de fundamentos dicotômicos e cristalizados (metáfora clássica do direito, da medicina, da teologia, da sociologia), mesmo que supostamente argumentem que defendem a vida, na realidade, ao desconsiderarem o processo de singularidade, tendem a dar mais valor aos interesses corporativos do que de fato à defesa da vida. Assim, apresentando grandes dicotomias entre o que dizem ser o grupo social e o lado individual, talvez por não apresentarem uma visão que se problematiza pelo caminho do "entre", tal como se pode observar especialmente nos trabalhos de Foucault e de Guattari, independentes de suas boas intenções, essas instituições podem estar colaborando para o aumento dos suicídios ${ }^{13}$. Nesse sentido, tal ponto cobra-nos pesquisas a fim de que se possa pensar os processos singulares por um modo de subjetividade menos dicotômico e cristalizado, diverso, quem sabe, do que foi discutido aqui pela perspectiva junguiana através das ideias de Hilmann.

4.5. A questão vincular com pendor para as relações sincréticas ou desestruturadas (pendor para as relações simbióticas ou pendor para relações esquizoides) não tem a pretensão de dar conta do objeto total da questão do suicídio, nem está sendo apresentada aqui como uma tentativa de "psicologizar" as relações sociais. Ao contrário, a questão vincular, além de estar sendo apresentada como a que também nos cobra mais pesquisas na área de suicidologia, quer apenas apontar que, quanto à questão do suicídio, dentre outras formas de se pensar a interconexão entre o dito psicológico e o lado do grupo, existe a possibilidade de se pensar isso a partir do agrupamento familiar (socialização primária). Enfim, assim como Durkheim afirmou que determinadas condições sociais criam comportamentos suicidas, a análise psicossocial, especialmente através da questão dos vínculos, aponta que a partir de determinadas relações, notadamente geradas nos grupos de socialização primária, podem gestar o aparecimento do comportamento autodestrutivo.

13 Para aprofundar a questão dos processos singulares da perspectiva de diferentes modos de subjetividades, os quais podem ser pensados pelo "entre" ou por uma subjetividade diversa à subjetividade hegemônica, problematizando isso junto ao estudo do suicídio, entre outras obras, sugerem-se as leituras: Bastos (2004), Fonseca (1995); Guattari (1988). 
Retomando o aforismo introdutório de Bispo do Rosário e analisando-o junto à dificuldade de se relacionar com vínculos estruturados (ou não-sincréticos), os quais nos fazem preponderantemente mais visíveis ou diferenciados, ele, que viveu meio século desvinculado de seus familiares, de dentro do hospício, através de seus trabalhos artísticos, quem sabe até para evitar suicídio, escreveu:“Faço o que faço (tento me mostrar pela arte) para não sucumbir à invisibilidade decorrente das relações sincréticas em minha vida".

\section{Suicides, Psychology and bonds: a psychosocial reading}

Abstract: Thinking suicide as an existential continuous with different degrees (first degrees - unconscious fantasies; intermediate degrees - suicide attempts; extreme degrees - fatal suicide), this article aims primarily at discussing the approaches of Freud and Jung on the subject. Moreover, it attempts to associate suicide to psychological processes, centered on bonding. These are basically seen as a bonding pattern initiated within the family group (primary socialization). Therefore, a pattern characterized by disruption (a difficulty to allow its members to differentiate themselves) at this first level tends to be repeated during the secondary socialization events: conjugal, work, education, religion relationships, etc. Thus, without proper support, in some cases, this difficulty can lead to attempts or fatal suicides. This issue as well as its psychosocial processes will be discussed particularly through the institutional approach of Bastos (2001 b), Bleger (1984), Guirado (2004).

Keywords: Suicides. Psychosocial process. Bonds.

\section{Suicides, Psychologie et liens une lecture psychosociale}

Résumé: En pensant le suicíde par un contínuum existentiel ayant des différents dégrés (premiers dégrés de suicide - dénoncés par des fantaisies inconscientes; des dégrés intermédiaires - caractérisés par des tentatives de suicide; des dégrés extrêmes - qui se font remarquer par le suicide fatal), cet article met à jour le débat par une perspective freudienne et jungienne. Mais, on cherche surtout à faire le rapport entre le suicide et un processus psychosocial, étudié par le lien social.Celui$\mathrm{ci}$, après tout, appris comme une norme de liaison, débute dans la famille (socialisation primaire). De cette façon, devant I' hypothèse d'avoir vécu dans une norme de liaison tendant à la déstructuration (ayant rapport à la difficuté de chaque membre se différencier), cette norme tend à se répéter par la socialisation secondaire: groupe de conjoints, de travail, d'éducation, de religion etc. Bref, sans l'appui nécessaire, dans 
quelques cas, cette difficulté mène aux tentatives de suicide et aux suicides. Cette discussion aussi bien que ce processus psychosocial y sont développés, principalment, par le point de vue institutionnel de Bastos (2001 b), Bleger (1984), Guirado (2004).

Mots-clés: Suicides. Processus Psychosocial. Liens.

\section{Suicidio, Psicología y vínculos: una lectura psico-social}

Resumen: Pensando el suicídio como un continuo existencial con diferentes grados (primeros grados de suicidio - manifestándose a través de fantasias inconscientes; grados intermedios - expresándose por tentativas de suicidio; grados extremos - destacándose por el suícidio fatal), este estudio lo discute desde la perspectiva de Freud y Jung. Pero se busca, sobre todo, relacionar el suicidio al proceso psico-social, estudiado aqui por el vínculo. Ese, básicamente apreendido como un padrón vincular, se inicia en la familia (socialización primaria). Así, frente a la hipótesis de haber vivido bajo el padrón vincular con tendéncia a la desectrutura (relacionado a la dificultad de cada miembro de diferenciarse), ese padrón tiende a repetirse por la socialización secundaria: grupo conyugal, grupo de trabajo, de educación, de religión etc. Finalmente, sin el apoyo devido, en algunos casos esa dificultad lleva a las tentativas y a los suicidios fatales. Tanto esa discusión como el proceso psico-social serán desarrollados aqui, principalmente, por la visión institucional de Bastos (2001b), Bleger (1984), Guirado (2004).

Palabras clave: Sucidios. Proceso psico-social.Vínculos.

\section{Referências}

Abadi, M. (1973). La fascinacion de la muerte. Buenos Aires: Paidos.

Bastos, R. L. (2001). Obra de arte e vida: psicologias sociais, diferentes subjetividades na estética da existência. Londrina, PR: Editora da Universidade Estadual de Londrina.

Bastos, R. L. (2004). Poética psicanálise. Rio de Janeiro: E-papers.

Bleger, J. (1977). Simbiose e ambigüidade. Rio de Janeiro: Francisco Alves.

Bleger, J. (1984). Psico-higiene e psicologia institucional. Porto Alegre: Artes Médicas.

Carvalho, M. M. (1996). Suicídio: a morte de si próprio. In M. H. P. F. Bromberg, M. J. Kovács, M. M. M. J. Carvalho \& V. A. Carvalho, Vida e morte: laços da existência (pp. 77-89). São Paulo: Casa do Psicólogo. 
Cassorla, R. (1981). Jovens que tentam o suicídio. Tese de Doutorado, Universidade Estadual de Campinas, Campinas, SP.

Cassorla, R. (1984). O que é o suicídio. São Paulo: Brasiliense.

Coimbra, M. C. C. (1997). O grito sufocado de morte dos Kaiowá e o conceito psicanalítico de pulsão. Monografia do Curso de Especialização em Psicologia Clínica e Teoria Psicanalítica, Pontifícia Universidade Católica de São Paulo, São Paulo.

Durkheim, E. (1971). El suicidio. Buenos Aires: Schapire.

Escritos do Bispo. (1988). Cadernos do NUPSO: Núcleo de Psiquiatria Social da Colônia Juliano Moreira, 1(1), 22-23.

Faria, F.M.(1997). Aquestão do suicídiona clínica. Umaleitura Winnicottiana. Dissertação de Mestrado, Pontifícia Universidade Católica de São Paulo. São Paulo.

Fenichel, O. (1981). Teoria psicanalítica das neuroses. São Paulo: Atheneu.

Féres-Carneiro, T. (1996). Família: diagnóstico e terapia. Petrópolis, RJ: Vozes.

Fonseca, M. A. (1995). Michel Foucault e a constituição do sujeito. São Paulo: Educ.

Freud, S. (1975). Sobre la psicogénesis de un caso de homosexualidad femenina. In S. Freud, Obras completas (Vol. 18). Buenos Aires: Amorrortu. (Trabalho original publicado em 1920)

Freud, S. (1988). Contribuciones para un debate sobre el suicidio. In S. Freud, Obras completas (Vol. 11). Buenos Aires: Amorrortu. (Trabalho original publicado em 1910)

Freud. S. (1989). Duelo y melancolía. In S. Freud, Obras completas (Vol. 14). Buenos Aires: Amorrortu. (Trabalho original publicado em 1917)

Guattari, F. (1988). O inconsciente maquínico. Campinas, SP: Papirus.

Guirado, M. (2004). Instituição e relações afetivas. São Paulo: Casa do Psicólogo.

Hendi, H. (1964). Suicide and Scandinavian. New York: Grune and Stratton.

Hidalgo, L. (1996). Arthur Bispo do Rosário: o senhor do labirinto. Rio de Janeiro: Rocco.

Hilmann, J. (1993). Suicídio e alma. Petrópolis, RJ: Vozes.

Jaffé, A., \& Frey-Rohn, L. (1995). A morte à luz da psicologia. São Paulo: Cultrix.

Ludemir, A. B. (1994). Suicídio, parassuicídio e desemprego. Jornal Brasileiro de Psiquiatria, 43(5), 267-269.

Ramos, E. (1974). Anatomia do suicídio. Arquivos Brasileiros de Psicologia Aplicada, 26(2), 79-98.

Santos-Stubbe, C. (1995). Suicídio como fator de alto risco entre as empregadas domésticas no Rio de Janeiro. Jornal Brasileiro de Psiquiatria, 44(10), 519-527.

Stubbe, H. (1995). Suicídios e tentativas de suicídio de criança. Psicologia Clínica, 7, 103-124.

Stubbe, H., \& Bojanovsky, J. (1982). Der depressive Mensch. Stuttgart: Enke. 
Rogério Lustosa Bastos, Professor Associado do Depto. de Métodos e Técnicas da ESS/Universidade Federal do Rio de Janeiro; Coordenador e Pesquisador do Núcleo de Estudos e Pesquisas em Tanatologia (NETPS/UFRJ); Doutor em Psicologia pela PUC/SP. Endereço eletrônico:rogeriolustosa@ufrj.br e rogerlustosa6@gmail.com

Recebido em: $20 / 05 / 2008$

Aceito em: 10/12/2008 